\title{
A risk factor for early wheezing in infants: rapid weight gain
}

\author{
Lijuan Yin ${ }^{1 * \dagger}$, Ye Song ${ }^{2+}$, Yongfang Liu $^{3}$ and Zehui Ye
}

\begin{abstract}
Background: The aim of this study was to investigate the correlation between rapid weight gain and early wheezing.

Methods: This study screened 701 infants with lower respiratory tract infection who were no more than 4 months from Jan 1st to Dec 31st in 2018. According to weight-for-age Z-value (WAZ), these infants were divided into the considerably slow weight gain group (group I), the normal weight gain group (group II) and the excessively rapid weight gain group (group III), respectively. The clinical characteristics, weight growth speeds and serum lipid levels were analyzed, and multivariable Logistic model was conducted to select significant variables.

Results: Our results showed that male $(\mathrm{OR}=1.841,95 \% \mathrm{Cl}$ : $1.233-2.751)$, family wheezing $(\mathrm{OR}=5.118,95 \% \mathrm{Cl}$ : 2.118-12.365), age $(\mathrm{OR}=1.273,95 \% \mathrm{Cl}: 1.155-1.403)$, eczema $(\mathrm{OR}=2.769,95 \% \mathrm{Cl}: 1.793-4.275)$, respiratory syncytial virus (RSV) infection ( $\mathrm{OR}=1.790,95 \% \mathrm{Cl}$ : 1.230-2.604), birth weight $(\mathrm{OR}=1.746,95 \% \mathrm{Cl}$ : $1.110-2.746)$ and total cholesterol (TC) $(\mathrm{OR}=1.027,95 \% \mathrm{Cl}: 1.019-1.036)$ and $\triangle \mathrm{WAZ}(\mathrm{OR}=1.182,95 \% \mathrm{Cl}: 1.022-1.368)$ were associated with early wheezing. Results indicated that serum TC $(P=0.018)$ and $\triangle W A Z(P=0.023)$ were positive correlation with wheezing days.
\end{abstract}

Conclusion: Besides male, family wheezing, age, eczema, RSV infection, birth weight and TC, the rapid weight growth as a risk factor should be concerned in the early wheezing infants.

Keywords: Infant, Wheezing, Rapid weight gain, Risk factor

\section{Background}

Wheezing, as a common clinical symptom of pediatric respiratory disease, is characterized by a continuous and sonorous voice in the expiratory phase, and sometimes appears in the inspiratory phase which results in increased respiratory rate [1]. Approximately $50 \%$ of children suffered from wheezing in infancy and childhood [2], and roughly $26 \%$ of 6265 babies had wheezing at least once within 18 months after birth from a prospective study [3]. Furthermore, about $30-40 \%$ of patients with recurrent wheezing were eventually diagnosed as bronchial asthma [4]. Therefore, it is necessary to explore the potentially risk factors to improve the pediatric respiratory system disease.

\footnotetext{
* Correspondence: ljyindoctor@sina.com

${ }^{+}$Lijuan Yin and Ye Song contributed equally to this work.

'Department of Respiratory Center, Children's Hospital of Chongqing Medical University, No.136 Zhongshan Second RoadYuzhong District, Chongqing 400014, People's Republic of China

Full list of author information is available at the end of the article
}

Infancy, especially the first year after birth, is one of peak periods of growth and development of the whole life. The rapid growth of the body signifies the further maturation and functional perfection of various organs. The pathogenesis of wheezing may be special and complicated in this period. Studies have confirmed that obesity and bronchial asthma suffered in adulthood, are closely connected with this period [5]. The previous study has manifested that weight-gain acceleration in early infancy was related to the increased risk of asthma symptoms in preschool children [6]. However, wheezing in infants is a heterogeneous disease, and the current mechanism of non-allergic wheezing is still unclear [7]. Several studies have reported that weight gain in infants is a risk factor for wheezing in childhood and even puberty [8-14]. To our best knowledge, however, there are few researches focusing on the relationship between the weight gain speed and wheezing in infants, especially early infantile. 
Herein, we investigated the demographic and related clinical characteristics, weight growth speeds and serum lipid levels of infants with early wheezing after birth. The primary purpose of this study was, thus, to identify the rapid weight growth as a potential risk factor for the early wheezing.

\section{Methods}

\section{Patients}

Totally 701 infants admitted to Children's Hospital of Chongqing Medical University were retrospectively screened in this study from Jan 1st to Dec 31st in 2018. This study was approved by the medical ethics committee of Children's Hospital of Chongqing Medical University, and the approval number was No.73/2019.

Hospitalized infants with lower respiratory tract infection who were no more than 4 months were included from Jan 1st to Dec 31st in 2018.

Patients who accorded with the following criteria were excluded: (1) premature delivery (gestational age $\leq 37$ weeks); (2) congenital cardiovascular anomaly; (3) bronchopulmonary dysplasia; (4) congenital tracheomalacia; (5) congenital stenosis of bronchus; (6) incomplete clinical data 1 , such as lack of blood biochemical indexes, or blood samples with requirements unmatched.

\section{Data collection}

The baseline data were collected including gender, age, birth weight and length, weight (ACS-20-YE electronic baby scale) and length (HX-II infant horizontal length measuring instrument) at admission, gestational age, delivery mode, feeding style, lactation diet, living environment, family history of obesity, allergy and wheezing, as well as history of individual eczema. The birth weight and weight at admission were analyzed to calculate the weight-for-age (WAZ) Z-value using WHO Anthro (version 3.0).

The data of illness condition were collected, such as the length of stay (LOS), date and season of onset, wheezing days, cases of severe wheezing, premier wheezing and repeated wheezing, days of intravenous hormone and common complications.

\section{Laboratory examination}

The pathogenic indicators were tested via the bacterial culture of nasopharyngeal secretions in combination with drug sensitivity test, enzyme-linked immunesorbent assay (ELISA) and polymerase chain reaction (PCR). The results consisted of respiratory syncytial virus (RSV), adenovirus (Adv), influenza virus A (IVA), influenza virus $B$ (IVB), parainfluenza virus (PIV-1, 2 and 3), mycoplasma pneumoniae (MP), chlamydia pneumoniae (CT) and cytomegalovirus (CMV).
The serum biochemical indices were detected utilizing Backman AU5800 automatic biochemistry analyzer, including total cholesterol (TC), triglyceride (TG), low density lipoprotein (LDL) and high density lipoprotein (HDL). Only when the children with fluid diet were fasted at least $3-4 \mathrm{~h}$ could the levels of blood lipids be collected. The fasting time was $6 \mathrm{~h}$ at least if a child ate solid food as supplements. When hemolysis or lipemia occurred in the specimens, the blood would be reextracted or directly excluded.

\section{$\triangle W A Z$}

The present study referred to the reported literature by Ong et al. [15], the equation is $\triangle W A Z=W A Z_{\text {at admission }}$ $\mathrm{WAZ}_{\text {at birth. }}$ The details are as follows: (1) $\triangle \mathrm{WAZ} \geq 0.67$ for excessively rapid weight gain; (2) $-0.67<\Delta W A Z<0.67$ for normal weight gain; (3) $\Delta \mathrm{WAZ} \leq-0.67$ for considerably slow weight gain. In accordance with the above standards, these infants were divided into the considerably slow weight gain group (group I), the normal weight gain group (group II) and the excessively rapid weight gain group (group III), respectively.

\section{Statistical analysis}

Statistical analysis was performed using SPSS 18.0 (SPSS, Inc., Chicago, IL). Measuring data were presented as the mean \pm standard and analyzed by ANOVA. Counting data were presented as $\mathrm{n}(\%)$ with Chi-square or Fisher test. The relationship between wheezing and related indicators was investigated using multivariate Logistic regression analysis. The association between wheezing days and serum TC, TG, HDL, LDL, $\triangle W A Z$ was analyzed by multiple stepwise regression analysis. The equation for inclusion and exclusion criteria was $0.15 . P<0.05$ was considered statistically significant.

\section{Results}

The baseline data in different weight growth patterns

A total of 735 cases were collected in this study, including 701 infants meeting the inclusion criteria. The primary characteristics of the participants were presented in Table 1. The parameters including age, gender, normal weight, low weight, overweight, eczema, severe wheezing, repeated wheezing, the length of onset (LOO), HDL and birth-weight $\mathrm{Z}$ score were no significantly statistical differences among the three groups $(P>0.05)$. The statistical differences among the three groups were shown in birth weight and length, weight and length at admission, family obesity, family wheezing, individual history of hypersensitivity, family hypersensitivity, wheezing, premier wheezing, the length of wheezing (LOW), LOS, TC, TG and LDL $(P<0.05)$.

We also investigated the seasons, systemic venous hormone injection and virus infections among wheezing patients 
Table 1 The baseline data of infants in different weight growth patterns

\begin{tabular}{|c|c|c|c|c|c|}
\hline Variables & Group I & Group II & Group III & $F / X^{2}$ & $P$ \\
\hline Case (n) & 237 & 243 & 221 & & \\
\hline Age (month, mean \pm SD) & $3.26 \pm 2.52$ & $3.23 \pm 1.64$ & $3.54 \pm 2.24$ & 1.385 & 0.251 \\
\hline \multicolumn{6}{|l|}{ Gender (n, \%) } \\
\hline Male & $163(68.78)$ & $170(69.96)$ & $153(69.23)$ & 0.080 & 0.961 \\
\hline Female & $74(31.22)$ & $73(30.04)$ & $68(30.77)$ & & \\
\hline Birth weight $(\mathrm{kg}$, mean $\pm \mathrm{SD})$ & $3.38 \pm 0.43$ & $3.26 \pm 0.44^{\#}$ & $3.1 \pm 0.40^{* \$}$ & 25.708 & $<0.001$ \\
\hline Weight at admission (kg, mean \pm SD) & $5.35 \pm 1.52$ & $6.33 \pm 1.28^{\#}$ & $7.24 \pm 1.71^{* \$}$ & 87.504 & $<0.001$ \\
\hline Birth length (cm, mean $\pm \mathrm{SD})$ & $50.11 \pm 1.36$ & $49.85 \pm 1.51^{\#}$ & $49.59 \pm 1.36^{\$}$ & 3.156 & 0.043 \\
\hline Length at admission ( $\mathrm{cm}$, mean $\pm \mathrm{SD}$ ) & $58.1 \pm 5.89$ & $59.65 \pm 5.80^{\#}$ & $59.16 \pm 6.08$ & 4.224 & 0.015 \\
\hline Normal weight (n, \%) & $226(95.36)$ & $232(95.47)$ & $214(96.83)$ & 0.769 & 0.681 \\
\hline Low weight (n, \%) & $11(4.64)$ & $9(3.70)$ & $3(1.36)$ & 4.096 & 0.129 \\
\hline Overweight (n, \%) & $0(0.00)$ & $2(0.82)$ & $4(1.81)$ & - & 0.087 \\
\hline Obesity (n, \%) & 0 & 0 & 0 & & \\
\hline \multicolumn{6}{|l|}{ Family obesity (n, \%) } \\
\hline Yes & $49(20.68)$ & $28^{\#}(11.52)$ & $22^{\$}(9.95)$ & 12.910 & 0.002 \\
\hline No & $188(79.32)$ & 215 (88.48) & 199 (90.05) & & \\
\hline \multicolumn{6}{|l|}{ Family wheezing $(\mathrm{n}, \%)$} \\
\hline Yes & $14(6.01)$ & $17(7.00)$ & $28^{* \$}(12.67)$ & 7.534 & 0.023 \\
\hline No & 219 (93.99) & $226(93.00)$ & $193(87.33)$ & & \\
\hline \multicolumn{6}{|l|}{ Individual history of allergy (n, \%) } \\
\hline Yes & $55(23.21)$ & $53(21.81)$ & $90^{* \$}(40.72)$ & 24.913 & $<0.001$ \\
\hline No & $182(76.79)$ & $190(78.19)$ & $131(59.28)$ & & \\
\hline \multicolumn{6}{|l|}{ Eczema (n, \%) } \\
\hline Yes & $60(25.32)$ & $70(28.81)$ & $64(28.96)$ & 0.996 & 0.608 \\
\hline No & $177(74.68)$ & $173(71.19)$ & $157(71.04)$ & & \\
\hline \multicolumn{6}{|l|}{ Family allergy (n, \%) } \\
\hline Yes & $11(4.64)$ & $14(5.76)$ & $53^{* \$}(23.98)$ & 54.086 & $<0.001$ \\
\hline No & $226(95.36)$ & $229(94.24)$ & $168(76.02)$ & & \\
\hline \multicolumn{6}{|l|}{ Wheezing (n, \%) } \\
\hline Yes & $105(31.16)$ & $128(52.67)$ & $136^{\$}(61.54)$ & 55.715 & $<0.001$ \\
\hline No & $232(68.84)$ & $115(47.33)$ & $85(38.46)$ & & \\
\hline \multicolumn{6}{|l|}{ Severe wheezing $(n, \%)$} \\
\hline Yes & $28(11.81)$ & $34(13.99)$ & $37(17.54)$ & 3.011 & 0.222 \\
\hline No & 209 (88.19) & 209 (86.01) & $174(82.46)$ & & \\
\hline \multicolumn{6}{|l|}{ Premier wheezing (n, \%) } \\
\hline Yes & $95(40.08)$ & $111(45.68)$ & $116^{\$}(95.87)$ & 110.451 & $<0.001$ \\
\hline No & $142(59.92)$ & $132(54.32)$ & $5(4.13)$ & & \\
\hline \multicolumn{6}{|l|}{ Repeated wheezing (n, \%) } \\
\hline Yes & $4(1.69)$ & $8(3.29)$ & $12(5.43)$ & 4.863 & 0.088 \\
\hline No & $233(98.31)$ & 235 (96.71) & $209(94.57)$ & & \\
\hline LOO (days, mean \pm SD) & $15.86 \pm 16.69$ & $14.73 \pm 17.14$ & $15.63 \pm 18.74$ & 0.276 & 0.759 \\
\hline LOW (days, mean \pm SD) & $7.44 \pm 10.79$ & $7.26 \pm 9.92$ & $11.02 \pm 13.35^{* \$}$ & 7.901 & $<0.001$ \\
\hline LOS (days, mean \pm SD) & $7.55 \pm 3.79$ & $6.65 \pm 2.78^{\#}$ & $6.78 \pm 2.52^{5}$ & 5.868 & 0.003 \\
\hline $\mathrm{TC}(\mathrm{mg} / \mathrm{dL}$, mean $\pm \mathrm{SD})$ & $120.91 \pm 32.46$ & $127.81 \pm 34.85^{\#}$ & $140.24 \pm 38.05^{* \$}$ & 17.69 & $<0.001$ \\
\hline
\end{tabular}


Table 1 The baseline data of infants in different weight growth patterns (Continued)

\begin{tabular}{llllll}
\hline Variables & Group I & Group II & Group III & F/X & $P$ \\
\hline TG $(\mathrm{mg} / \mathrm{dL}$, mean $\pm \mathrm{SD})$ & $56.49 \pm 29.22$ & $50.41 \pm 21.96^{\#}$ & $56.3 \pm 27.45^{*}$ & 4.116 & 0.017 \\
$\mathrm{HDL}(\mathrm{mg} / \mathrm{dL}$, mean $\pm \mathrm{SD})$ & $45.84 \pm 19.97$ & $47.47 \pm 18.99$ & $47.02 \pm 19.47$ & 0.445 & 0.640 \\
$\mathrm{LDL}(\mathrm{mg} / \mathrm{dL}$, mean $\pm \mathrm{SD})$ & $59.03 \pm 23.96$ & $59.43 \pm 21.84^{\#}$ & $67.57 \pm 25.80^{*}$ & 9.254 & $<0.001$ \\
Birth-weight Z score & $-1.50 \pm 1.21$ & $-0.18 \pm 1.04$ & $0.88 \pm 0.99$ & 1.172 & 0.069 \\
\hline
\end{tabular}

LOO The length of onset, LOW The length of wheezing, LOS The length of stay, TC Total cholesterol, TG Triglyceride, HDL High density lipoprotein, LDL Low density lipoprotein

-: Using Fisher test

\#: Group I vs Group II, $P<0.05$; $^{*}$ : Group II vs Group III, $P<0.05 ;$ ' : Group I vs Group III, $P<0.05$

in this study. The results suggested that the incidence of wheezing in spring (52.9\%) was higher than other seasons, and the statistical differences were observed among the three groups $\left(\chi^{2}=8.71, P=0.013\right)$. The average days of systemic venous hormone injection were $2.07 \pm 3.59$, and there were no evident differences among the three groups $(\mathrm{F}=2.922$, $P=0.054)$. Totally 334 cases suffered from positive viral infections. The viruses with a highly positive infection rate were RSV $\left(\chi^{2}=3.36, P=0.187\right)$, PIV-3 $\left(\chi^{2}=0.76, P=0.68\right)$ and IVA $\left(X^{2}=1.06, P=0.59\right)$ in turn. The detectable rates of three viruses in infants with wheezing were shown no differences among the three groups $(P>0.05)$.

In addition, the characteristics of mothers in different weight growth patterns were analyzed in Table 2 . The gestational age and pregnant frequency were statistically significant among the three groups $(P<0.05)$. However, no significant differences in parity, natural delivery, caesarean, exclusive breastfeeding, artificial feeding, mixed feeding, breastfeeding and complementary feeding were revealed among the three groups $(P>0.05)$.

\section{Multivariate logistic regression analysis for infants with early wheezing}

The value of risk factors to predict early wheezing was further analyzed using multivariable Logistic regression, as presented in Table 3. Statistically obvious differences were shown in the male $(\mathrm{OR}=1.841,95 \% \mathrm{CI}: 1.233-2.751)$, family wheezing ( $\mathrm{OR}=5.118,95 \% \mathrm{CI}$ : $2.118-12.365)$, age

Table 2 The characteristics of mothers in different weight growth patterns

\begin{tabular}{|c|c|c|c|c|c|}
\hline Variables & Group I & Group II & Group III & $F / X^{2}$ & $P$ \\
\hline Case (n) & 237 & 243 & 221 & & \\
\hline Gestational age (weeks, mean \pm SD) & $38.43 \pm 1.48$ & $38.25 \pm 1.24$ & $38.11 \pm 1.27^{\$}$ & 3.165 & 0.043 \\
\hline Pregnant frequency $(n$, mean $\pm S D)$ & $1.87 \pm 1.11$ & $2.06 \pm 1.43$ & $2.24 \pm 1.47^{\$}$ & 4.450 & 0.012 \\
\hline Parity $(n$, mean $\pm S D)$ & $1.38 \pm 0.56$ & $1.35 \pm 0.56$ & $1.42 \pm 0.59$ & 1.016 & 0.363 \\
\hline Natural delivery (n, \%) & $114(48.10)$ & $113(46.50)$ & $92(41.63)$ & 2.081 & 0.353 \\
\hline Caesarean (n, \%) & $123(51.90)$ & $130(53.50)$ & $129(58.37)$ & & \\
\hline \multicolumn{6}{|l|}{ Exclusive breastfeeding ( $n, \%)$} \\
\hline Yes & $63(26.58)$ & $69(28.40)$ & $52(23.53)$ & 1.436 & 0.488 \\
\hline No & $174(73.42)$ & $174(71.60)$ & $169(76.47)$ & & \\
\hline \multicolumn{6}{|l|}{ Artificial feeding $(n, \%)$} \\
\hline Yes & $68(28.94)$ & $77(31.69)$ & $59(26.70)$ & 1.405 & 0.495 \\
\hline No & $167(71.06)$ & $166(68.31)$ & $162(73.30)$ & & \\
\hline \multicolumn{6}{|l|}{ Mixed feeding (n, \%) } \\
\hline Yes & $106(44.73)$ & $97(39.92)$ & $110(49.77)$ & 4.550 & 0.103 \\
\hline No & $131(55.27)$ & $146(60.08)$ & $111(50.23)$ & & \\
\hline \multicolumn{6}{|l|}{ Breastfeeding (n, \%) } \\
\hline Yes & $169(71.31)$ & $166(68.31)$ & $162(73.30)$ & 1.426 & 0.490 \\
\hline No & $68(28.69)$ & 77 (31.69) & $59(26.70)$ & & \\
\hline \multicolumn{6}{|l|}{ Complementary feeding (n, \%) } \\
\hline Yes & $38(16.03)$ & $33(13.58)$ & $30(13.57)$ & 0.767 & 0.681 \\
\hline No & 199 (83.97) & $210(86.42)$ & $191(86.43)$ & & \\
\hline
\end{tabular}

\#: Group I vs Group II, $P<0.05 ;{ }^{*}:$ Group II vs Group III, $P<0.05 ;$ \$: Group I vs Group III, $P<0.05$ 
Table 3 Multivariate logistic regression analysis for infants with early wheezing

\begin{tabular}{lllllll}
\hline variables & $\beta$ & S.E & $X^{2}$ & $P$ & $O R$ & $95 \% \mathrm{Cl}$ \\
\hline Male & 0.610 & 0.205 & 8.886 & 0.003 & 1.841 & $1.233-2.751$ \\
Family wheezing & 1.633 & 0.450 & 13.158 & $<0.001$ & 5.118 & $2.118-12.365$ \\
Countryside & -0.721 & 0.198 & 13.297 & $<0.001$ & 0.486 & $0.330-0.717$ \\
Age & 0.241 & 0.050 & 23.723 & $<0.001$ & 1.273 & $1.155-1.403$ \\
$\Delta$ WAZ & 0.167 & 0.074 & 5.064 & 0.024 & 1.182 & $1.022-1.368$ \\
Eczema & 1.018 & 0.222 & 21.098 & $<0.001$ & 2.769 & $1.793-4.275$ \\
RSV infection & 0.582 & 0.191 & 9.242 & 0.002 & 1.790 & $1.230-2.604$ \\
Birth weight & 0.557 & 0.231 & 5.820 & 0.016 & 1.746 & $1.110-2.746$ \\
TC & 0.027 & 0.004 & 38.333 & $<0.001$ & 1.027 & $1.019-1.036$ \\
TG & -0.006 & 0.004 & 2.159 & 0.142 & 0.994 & $0.987-1.002$ \\
HDL & -0.024 & 0.005 & 18.620 & $<0.001$ & 0.977 & $0.966-0.987$ \\
LDL & 0.005 & 0.006 & 0.817 & 0.366 & 1.005 & $0.994-1.017$ \\
Constant & -4.230 & 0.928 & 20.803 & $<0.001$ & & \\
\hline
\end{tabular}

RSV Respiratory syncytial virus, TC Total cholesterol, TG Triglyceride, LDL Low density lipoprotein, HDL High density lipoprotein

$(\mathrm{OR}=1.273, \quad 95 \% \mathrm{CI}:$ 1.155-1.403), $\Delta \mathrm{WAZ} \quad(\mathrm{OR}=1.182$, 95\%CI: 1.022-1.368), eczema (OR $=2.769$, 95\%CI: $1.793-$ 4.275), RSV infection (OR $=1.790,95 \% \mathrm{CI}: 1.230-2.604)$, birth weight $(\mathrm{OR}=1.746,95 \% \mathrm{CI}$ : $1.110-2.746)$ and $\mathrm{TC}$ (OR $=1.027$, 95\%CI: 1.019-1.036). While no evidence demonstrated that countryside, TG, HDL, LDL may server as the risk factors for early wheezing infants in our research.

\section{Regression analysis between wheezing days and serum lipid parameters}

Regression analysis was used to assess the relationships between wheezing days and serum lipid parameters in Table 4. Results indicated that serum TC $(P=0.018)$ and $\triangle \mathrm{WAZ}$ $(P=0.023)$ were positively correlated with wheezing days. Furthermore, no distinct connection was discovered between TG, HDL, LDL and wheezing days $(P=0.706,0.056$ and 0.500 , respectively).

Table 4 Regression analysis between wheezing days and related indicators

\begin{tabular}{|c|c|c|c|c|}
\hline \multirow{2}{*}{$\begin{array}{l}\text { Dependent } \\
\text { variable }\end{array}$} & \multirow{2}{*}{$\begin{array}{l}\text { Independent } \\
\text { variables }\end{array}$} & \multicolumn{2}{|c|}{ Regression coefficient $(\beta)$} & \multirow[t]{2}{*}{$P$} \\
\hline & & $\beta$ value & Standard $\beta$ & \\
\hline \multirow[t]{5}{*}{ Wheezing days ${ }^{a}$} & $\mathrm{TC}$ & 0.038 & 0.135 & 0.018 \\
\hline & TG & 0.005 & 0.014 & 0.706 \\
\hline & $\mathrm{HDL}$ & -0.039 & -0.075 & 0.05 \\
\hline & LDL & 0.015 & 0.035 & 0.500 \\
\hline & $\triangle W A Z$ & 1.193 & 0.126 & 0.02 \\
\hline
\end{tabular}

TC Total cholesterol, TG Triglyceride, LDL Low density lipoprotein, HDL High density lipoprotein

${ }^{a}$ Adjusting age, gender, birth weight, weight at admission, feeding style and lactation diet

\section{Discussion}

Wheezing is a common chronic respiratory disease among children worldwide, and is also a worried event for parents and pediatricians because it may develop into asthma. The current study evaluated the potential predicting factors for infants with early wheezing. We retrospectively investigated 701 under 4 months infants hospitalized for lower respiratory tract infection. The findings suggested that the rapid weight gain could be a potential risk factor for infants with early wheezing.

Infancy, as a key stage, not only has profound effects on the physical growth and development, but also influences the occurrence and development of chronic diseases such as cardiovascular disease, hypertension and diabetes at various ages $[5,16,17]$. It is the fact that the first 6 months after birth is a high-risk period of overweight formation $[18,19]$. Our study discovered the children in group III had lower birth weight and length, while those in group I had higher birth weight and length. When the infants were approximately at 4 months, the weight in group III was higher than other two groups, which had obvious catch-up growth trends. Theoretically, rapid weight gain may lead to different degrees of adipose tissue acquisition, and we observed the TC, LDL and TG in group III were distinctly higher than other two groups, in which TC was positively correlated with wheezing and wheezing days $(P<0.05)$, suggesting that lipid metabolism is enhanced with the increase of weight gain speed. Abnormal or disordered lipid metabolism is a common issue in adults and infants. However, to our best knowledge, there are lack of uniform standards for blood lipid detection in infants and normal standard value for the infants under 2 years old in China nowadays. In this study, no more than 20 cases of high blood lipids were found in all blood lipid indicators. The lipid disorder is temporary in infancy, and the level of lipid metabolism gradually decreases to the normal after one and a half years [20].

We discovered that the breastfeeding was a common feeding pattern, and no statistical differences were found among the three groups. Clinical observations displayed that the frequency of daily intake in group III was more than that other two groups. Nevertheless, it still needs further observation whether there exist differences in the growth speed of infants owing to lack of feeding knowledge. With the extension of breastfeeding time, the weight of mothers was on the decline, it may be selffat catabolism of mothers leading to high breast milk fat content, which causes children to receive a high-fat diet from mothers. Imperfect synthetic function of HDL in small intestine and liver can result in enhancive cholesterol accumulation, elevated blood lipids containing the TC level, relatively increased LDL-carried cholesterol for the synthesis of cell membranes and steroid hormones, 
and accumulation of cell membranes and cholesterol of vital organs such as airway. Studies have reported that lipid metabolism has an impact on lung diseases. The data for animal experiments have observed that cholesterol transporters such as ABCG1, apoE and LXR are involved in immune defense of the respiratory tract, resulting in Th1/Th2 imbalance and elevated airway neutrophils and IL-17, which would lead to the susceptibility of respiratory tract infections [21, 22]. The clinical observation of this study discovered that neutrophils were mainly increased in bronchoalveoar lavage fluid (BALF) among wheezing infants, but not eosinophils. It is indicated that cholesterol transport promotes the neutrophil chemotaxis and upregulation of inflammatory cytokines which may participate in the development of wheezing [21].

Studies found that nearly half of children had wheezing within 1 year after birth, especially no more than 6 months [4]. To date scholars mostly had focused on investigating the effects of weight gain on wheezing or recurrent wheezing in different periods [12, 23-26], meanwhile several researchers found that growth speed was a risk factor for respiratory disease among children [27]. Our results displayed the there was no statistical significance among the infants with normal weight, low weight and overweight. It is indicated that the occurrence of wheezing is not relevant to weight [27], but may be associated with growth speed, which is in accordance with previous reports [10, 28, 29]. Evidences demonstrated that the weight growth speed might serve as a potential influencing factor in obesity [19], pulmonary function decline [29], bronchial asthma [30], cardiovascular disease [16], and type 1 diabetes [17] during infancy. Although various assessment criteria for wheezing have been used in recent years, rapid weight gain may also be considered as a hazardous element in wheezing [30,31]. The data from Table 4 we obtained that wheezing days were positively correlated with the weight gain $(P<0.05)$. However, the mechanism between rapid weight gain and wheezing among infants is currently unclear.

Differences between intrauterine environment and postnatal environment may lead to the development of postnatal diseases [32, 33], and the compensatory growth appeared due to the intrauterine growth in unfavorable intrauterine environment. While rapid compensatory growth may be detrimental to the future health [13], rapid weight gain can result in relatively poor lung development, and airway stenosis can increase the incidence and severity of wheezing $[13,29]$. Studies showed that rapid weight gain, especially in the first year after birth, was significantly related to the frequency and degree of wheezing [26, 34]. Early reports demonstrated that allergy and eczema can enhance the risk of wheezing or asthma [35, 36]. The data of our research revealed the proportions of the individual history of hypersensitivity and eczema were higher in group III. Furthermore, the viral infection as a suspicious factor was considered in several researches. RSV is the most common pathogen for infantile wheezing, with $46.5 \%$ of infection rate, but no statistical differences were discovered among the three groups. It is indicated that RSV infection was involved in the occurrence and development of wheezing, while it may be not a major factor in infants with early wheezing. In addition, excessively rapid weight gain may cause changes in lung development, including alveolar number, lung weight and immune system, especially adverse changes in immune function can increase the occurrence of asthma in children. In this study, we found an obvious family characteristic among infants in group III. The infants had a positive family history of wheezing, particularly first-degree relatives, suggesting family genetic predisposition in these individuals. The previous protocol mentioned that wheezing may be associated with the mitochondrial gene variation, especially the father's genes [17]. These still need further in-depth researches and discussions in the future.

The superiority of this study was that few previous researches had investigated the relationship between the weight gain speed and wheezing in infants, especially early infantile wheezing in Chinese population. It was the fact that rapid weight gain may be a risk factor in infants with early wheezing, which is beneficial for pediatricians to effectively identify wheezing children. There were some limitations that should be warranted caution for interpreting the data in this work. Firstly, our investigation was a retrospective study based on a single center, which is lack of parental serum lipid, antenatal and postnatal smoking, and intrauterine growth retardation (IUGR) or small for gestational age infant (SGA) collection. Secondly, there were no clear biologic targets as observation indicators to indicate the association between weight growth speed and infants with early wheezing. Thus, multicenter studies with larger samples should be needed for further verification of the role of weight growth speed in early wheezing infants in clinic.

\section{Conclusion}

The current study accessed the potential risk factors for early wheezing infants aged no more than 4 months. We analyzed the demographic and related clinical characteristics, weight growth speeds and serum lipid levels of infants with early wheezing after birth. Besides male, family wheezing, age, eczema, RSV infection, birth weight and TC, the rapid weight growth as a risk factor should be concerned in the early wheezing infants. 


\section{Abbreviations}

Cl: Confidence interval; HDL: High density lipoprotein; LDL: Low density lipoprotein; LOO: The length of onset; LOS: The length of stay; LOW: The length of wheezing; OR: Odds ratio; RSV: Respiratory syncytial virus; TC: Total cholesterol; TG: Triglyceride

\section{Acknowledgements}

Not applicable.

\section{Authors' contributions}

LY and YS has been involved in study design, data collection, statistical analysis, data interpretation and manuscript preparation. $Y L$ and $Z Y$ have been involved in data collection, statistical analysis and data interpretation. All authors read and approved the final manuscript.

\section{Funding}

This study has received no funding.

\section{Availability of data and materials}

The datasets used and/or analyzed during the current study are available from the corresponding author on reasonable request.

\section{Ethics approval and consent to participate}

This research was approved by the medical ethics committee of Children's Hospital of Chongqing Medical University, and the approval number was No.73/2019.

\section{Consent for publication}

Not applicable.

\section{Competing interests}

The authors declare that they have no competing interests.

\section{Author details}

${ }^{1}$ Department of Respiratory Center, Children's Hospital of Chongqing Medical University, No.136 Zhongshan Second RoadYuzhong District, Chongqing 400014, People's Republic of China. ${ }^{2}$ Department of Pediatrics, The First Affiliated Hospital of Air Force Military Medical University, Xi'an 710000, People's Republic of China. ${ }^{3}$ Department of Nutrition, Children's Hospital of Chongqing Medical University, Chongqing 400014, People's Republic of China.

Received: 19 May 2019 Accepted: 12 September 2019 Published online: 15 October 2019

\section{References}

1. Bush A, Grigg J, Saglani S. Managing wheeze in preschool children. BMJ. 2014;348(348):g15.

2. Martinez FD, Wright AL, Taussig LM, Holberg CJ, Halonen M, Morgan WJ. Asthma and wheezing in the first six years of life. The group health medical associates. N Engl J Med. 1995;332(3):133-8.

3. Henderson J, Granell R, Heron J, Sherriff A, Simpson A, Woodcock A, et al. Associations of wheezing phenotypes in the first 6 years of life with atopy, lung function and airway responsiveness in mid-childhood. Thorax. 2008; 63(11):974-80.

4. Alvarez-Alvarez I, Niu H, Guillen-Grima F, Aguinaga-Ontoso I. Meta-analysis of prevalence of wheezing and recurrent wheezing in infants. Allergol Immunopathol (Madr). 2018;46(3):210-7.

5. Gillman MW. Developmental origins of health and disease. N Engl J Med. 2005:353(17):1848-50.

6. Sonnenschein-van der Voort AMM, Jaddoe WW, Raat H, Moll HA, Hofman $\mathrm{A}$, de Jongste $\mathrm{JC}$, et al. Fetal and infant growth and asthma symptoms in preschool children the generation R study. Am J Respir Crit Care Med. 2012; 185(7):731-7.

7. Strina A, Barreto ML, Cooper PJ, Rodrigues LC. Risk factors for non-atopic asthma/wheeze in children and adolescents: a systematic review. Emerg Themes Epidemiol. 2014;117. Strina A, Barreto ML, Cooper PJ, Rodrigues LC. Risk factors for non-atopic asthma/wheeze in children and adolescents: a systematic review. Emerg Themes Epidemiol. 2014;11:5-15.

8. Schultz ES, Hallberg J, Andersson N, Thacher JD, Pershagen G, Bellander T, et al. Early life determinants of lung function change from childhood to adolescence. Respir Med. 2018;139:48-54.
9. Mebrahtu TF, Feltbower RG, Parslow RC. Effects of birth weight and growth on childhood wheezing disorders: findings from the Born in Bradford Cohort. BMJ Open. 2015;5(11):e009553.

10. Voort A, Arends LR, Jongste JC, Annesi-Maesano I, Arshad SH, Barros H, et al. Preterm birth, infant weight gain, and childhood asthma risk: a meta-analysis of 147,000 European children. J Allergy Clin Immunol. 2014;133(5):1317-29.

11. Rzehak P, Wijga AH, Keil T, Eller E, Bindslev-Jensen C, Smit HA, et al. Body mass index trajectory classes and incident asthma in childhood: results from 8 European birth cohorts-a global allergy and asthma European network initiative. J Allergy Clin Immunol. 2013;131(6):1528-36.

12. Flexeder C, Thiering E, Bruske I, Koletzko S, Bauer CP, Wichmann HE, et al. Growth velocity during infancy and onset of asthma in school-aged children. Allergy. 2012;67(2):257-64.

13. van der Gugten AC, Koopman M, Evelein AMV, Verheij TJM, Uiterwaal C, van der Ent CK. Rapid early weight gain is associated with wheeze and reduced lung function in childhood. Eur Respir J. 2012;39(2):403-10.

14. Taveras EM, Rifas-Shiman SL, Camargo CA, Gold DR, Litonjua AA, Oken E, et al. Higher adiposity in infancy associated with recurrent wheeze in a prospective cohort of children. J Allergy Clin Immunol. 2008;121(5):1161-6.

15. Ong KK, Ahmed ML, Emmett PM, Preece MA, Dunger DB. Association between postnatal catch-up growth and obesity in childhood: prospective cohort study. BMJ. 2000;320(7240):967-71.

16. Leunissen RWJ, Kerkhof GF, Stijnen T, Hokken-Koelega A. Timing and tempo of first-year rapid growth in relation to cardiovascular and metabolic risk profile in early adulthood. JAMA. 2009;301(21):2234-42.

17. Harder T, Roepke K, Diller N, Stechling Y, Dudenhausen JW, Plagemann A. Birth weight, early weight gain, and subsequent risk of type 1 diabetes: systematic review and meta-analysis. Am J Epidemiol. 2009;169(12):1428-36.

18. Taveras EM, Rifas-Shiman SL, Belfort MB, Kleinman KP, Oken E, Gillman MW. Weight status in the first 6 months of life and obesity at 3 years of age. Pediatrics. 2009;123(4):1177-83.

19. Savage JS, Birch LL, Marini M, Anzman-Frasca S, Paul IM. Effect of the INSIGHT responsive parenting intervention on rapid infant weight gain and overweight status at age 1 year a randomized clinical trial. JAMA Pediatr. 2016;170(8):742-9.

20. Nilsson A, Ortqvist E, Lagercrantz H, NilssonEhle P, Henter Jl. Transient hypertriglyceridemia of infancy. Acta Paediatr. 1996;85(12):1508-10.

21. Fessler MB. A new frontier in immunometabolism cholesterol in lung health and disease. Ann Am Thorac Soc. 2017;14:S399-405.

22. Suratt BT, Ubags NDJ, Rastogi D, Tantisira KG, Marsland BJ, Petrache I, et al. An official American Thoracic Society workshop report: obesity and metabolism an emerging frontier in lung health and disease. Ann Am Thorac Soc. 2017;14(6):1050-9.

23. Magnusson JO, Kull I, Mai XM, Wickman M, Bergstrom A. Early childhood overweight and asthma and allergic sensitization at 8 years of age. Pediatrics. 2012;129(1):70-6.

24. Scholtens S, Wijga AH, Seidell JC, Brunekreef B, de Jongste JC, Gehring U, et al. Overweight and changes in weight status during childhood in relation to asthma symptoms at 8 years of age. J Allergy Clin Immunol. 2009;123(6):1312-8.

25. Wandalsen GF, Borges LV, Barroso N, Rota R, Suano F, Mallol J, et al. Gender differences in the relationship between body mass index (BMI) changes and the prevalence and severity of wheezing and asthma in the first year of life. Allergol Immunopathol (Madr). 2015;43(6):562-7.

26. Wandalsen GF, Borges LV, Barroso N, Navarr ACP, Suano-Souza F, Prestes EX, et al. Association between weight gain and the prevalence and severity of wheezing and asthma in the first year of life. Rev Port Imunoalergologia. 2013;21(1):19-26.

27. Korte-de Boer D, Mommers M, Thijs C, Jaminon M, Jansen M, Mujakovic S, et al. Early life growth and the development of preschool wheeze, independent from overweight: the LucKi birth cohort study. J Pediatr. 2015; 166(2):343-9.

28. Wandalsen GF, Chong-Neto HJ, de Souza FS, Solé D, Bacharier LB. Early weight gain and the development of asthma and atopy in children. Curr Opin Allergy Clin Immunol. 2014;14(2):126-30.

29. den Dekker HT, Voort A, de Jongste JC, Anessi-Maesano I, Arshad SH, Barros $\mathrm{H}$, et al. Early growth characteristics and the risk of reduced lung function and asthma: a meta-analysis of 25,000 children. J Allergy Clin Immunol. 2016;137(4):1026-35.

30. Casas M, den Dekker HT, Kruithof CJ, Reiss IK, Vrijheid M, Sunyer J, et al. The effect of early growth patterns and lung function on the development of childhood asthma: a population based study. Thorax. 2018;73(12):1137-45. 
31. Popovic M, Pizzi C, Rusconi F, Galassi C, Gagliardi L, De Marco L, et al. Infant weight trajectories and early childhood wheezing: the NINFEA birth cohort study. Thorax. 2016;71(12):1091-6.

32. Turner S, Prabhu N, Danielian P, McNeill G, Craig L, Allan K, et al. First- and second-trimester fetal size and asthma outcomes at age 10 years. Am J Respir Crit Care Med. 2011;184(4):407-13.

33. Barker DJP, Gluckman PD, Godfrey KM, Harding JE, Owens JA, Robinson JS. Fetal nutrition and cardiovascular-disease in adult life. Lancet. 1993; 341(8850):938-41.

34. Rona RJ, Smeeton NC, Bustos P, Amigo H, Diaz PV. The early origins hypothesis with an emphasis on growth rate in the first year of life and asthma: a prospective study in Chile. Thorax. 2005;60(7):549-54.

35. Gould HJ, Sutton BJ. IgE in allergy and asthma today. Nat Rev Immunol. 2008;8(3):205-17.

36. Cassell HR, Stern DA, Wright AL, Martinez FD. Early onset eczema and the association with early onset asthma. J Allergy Clin Immunol. 2018;141(2):AB130.

\section{Publisher's Note}

Springer Nature remains neutral with regard to jurisdictional claims in published maps and institutional affiliations.

Ready to submit your research? Choose BMC and benefit from:

- fast, convenient online submission

- thorough peer review by experienced researchers in your field

- rapid publication on acceptance

- support for research data, including large and complex data types

- gold Open Access which fosters wider collaboration and increased citations

- maximum visibility for your research: over $100 \mathrm{M}$ website views per year

At BMC, research is always in progress.

Learn more biomedcentral.com/submissions 